\title{
Ideology at Work in (the Production of) the News on Ethnic Minorities
}

\author{
Ferruh Y1lmaz \\ Correspondence: Ferruh Yilmaz, Department of Communication, Tulane University, 219 Newcomb Hall, 1229 \\ Broadway, New Orleans, LA 70118, USA.
}

Received: May 31, 2013 Accepted: June 13, 2013 Available online: January 26, 2014

doi:10.11114/smc.v2i1.325 URL: http://dx.doi.org/10.11114/smc.v2i1.325

\begin{abstract}
This paper analyzes how everyday production routines and journalistic conventions as well as ideological assumptions about minorities and about the newspaper's readership all play a role in the production of an ordinary story about Latino labor leader. The concept of 'newsworthiness' is a major rhetorical source in these negotiations between the reporter and the editor, and the news sources. Newsworthiness is flexibly defined and redefined through complex negotiations in order to fit the story into one of the basic journalistic forms (human-interest, conflict or deviance story). In this case, a potential conflict story is turned into a human-interest story to get a positive story about Latino population into the newspaper. The analysis is based on my ethnographic observations on the San Diego Union Tribune during a routine news production day, where I followed a reporter while he was producing an ordinary news article on his beat, Latino Affairs.
\end{abstract}

Keywords: news production, ideology, minorities, journalism, Latin American

\section{Introduction: The Wall between News and Opinion}

"Journalists are so aware of the wall between news and opinion that they assume readers also are cognizant of the separation," wrote Gina Lubrano, the reader representative on The Union Tribune on July 15, 2002. She was addressing the readers who complained about bias in the newspaper. Her point was that some readers did not know the difference and therefore took opinion expression for bias in the newspaper. "What's the difference between writers of columns and writers of news article?" she asked rhetorically: "Those who write opinion, myself included, are paid to have a point of view. It could be said that reporters, whose job it is to report the news, are paid not to express their opinions in print ... consider this newspaper's coverage of the baseball stadium issue. Reporters, who have their own opinion, are obliged by their craft to put their biases aside and report all sides of the issue, including those with which they disagree ... Uninformed criticisms are easy for journalists to dismiss, but what's not easy to ignore is that the misperceptions goes out to others who believe it because they, too, do not understand there is a marked separation between the opinion pages and news in the first place."

These lines are a typical reflection of journalists' understanding of news as unbiased descriptions of events as opposed to opinion columns. Lubrano's lines make perfectly sense in terms of the dichotomy between opinion pages such as editorials and news. At the root of this dichotomy is the referential view of language and meaning, (i.e., the ideas that language is a nomenclature, which is in on-to-one relations to objects they describe), and related to this view the assumption that opinions are mental evaluations of external realities that are readily available through descriptions. However, opinions and descriptions may not be as easily separable as the dichotomy implies. Our descriptions of the world already entail evaluations (Potter and Wetherell, 1987). As such, any utterance - be it a news report or simple eyewitness accounts - is inherently ideological, i.e., it is a description of the world that is constructed against other (potentially alternative) descriptions of the same reality.

This article illustrates this rather theoretical abstraction through an empirical analysis of the kind of negotiations that are involved in the production of a news article. The essay is based on my ethnographic observations on the San Diego Union Tribune, where I followed a reporter, Leonel Sanchez, while he was producing an ordinary news article on his beat, Latino Affairs. The story was published in San Diego Union Tribune Friday, November 17, 2000 with the title, "Blood donations will honor labor leader."

\section{Ethnography and News as the Discourse of Reality}

Reality descriptions are never merely reflections of the world as it is but construct the very world they speak of. Once we take a detailed and careful look at the way reality is described in utterances, the distinction between mere 
descriptions of reality (or reality itself as it were) and evaluations of (or opinions on) that reality is difficult to sustain. The nature of reality is never readily accessible except through descriptions in language, and consequently reality can be described in different ways. We are trained to take a statement such as "blacks are overrepresented in crime statistics" as a mere descriptive act given the statement is warranted in statistics, (that is we are trained to understand a neutral description of reality as that which can be verified). Yet the very act of talking about crime in terms of color difference is to imply that "color" matters most among other "variables." The same basic assumption (color as an explaining factor) is indeed also at play when those statistics are made. So, the proof for the claim is itself a product of the same articulatory process, rather than a reflection of a token reality. Our utterances are full of such statements that invoke reality outside our mental evaluations. News is the discourse of reality.

In line with much critical media studies, I do not see news as simple descriptions of the world out there but as an ideological medium that provides framework for interpreting and reacting to social and political matters (Hallin, 1994, p. 90) despite the strong belief among journalists that it is possible to report events from non-political standpoint through "neutral" criteria of newsworthiness (Hallin, 2000, p. 220) as Lubrano's article which I cited in the introduction perfectly illustrates. Merely analyzing the media output to illustrate this point would be insensitive to "difference between the immediate values in the news and the value implications of the news ... journalists are sensitive to the difference between the news and its implications, but critics ... are not always equally so, and the values they may see in the news and among journalists are actually implications" (Gans, 1980, p. 40). That is, although demonstrating the ideological implications of a news story through a textual analysis may illuminate how ideology works in the text, such an analysis will not say much about how and why those ideological premises enter the text and why and what other potential or actual rationales are excluded. Besides, news stories are rarely homogenous texts; they consist of an intertextuality of different discourses (Fairclough, 1992, 1995). Furthermore, a textual analysis is limited in illuminating the structural, organizational and occupational constraints that in various degrees all have an influence upon how the news story is shaped. My ethnographic observations allowed me to analyze these constraints and ongoing negotiations between the reporter and his editor; his sources; and his imagined audience; and finally with his professional values and with himself in the process of getting the story into the paper.

My main argument in this article is that the story about the labor leader Dolores Huerta may have other ideological implications than the story intends. The reporter intends to write a positive story about the Latino population by which he hopes to challenge the stereotypical portrayals of them in the media. In order to get the story into the newspaper, he decides to treat the story as a "human interest story." This decision, however, renders his project of writing a positive story ambiguous in its effects because making it into a human interest story de-ethnicizes and de-politicizes the protagonists of the story. Other constraints also play a role in making the desired effect ambiguous: feminizing the main protagonist to fit her into the category of human-interest news contributes to the de-politicization of the story. His subscription to some taken-for-granted criteria of newsworthiness (in this case who-what-why) helps him escape any potential accusation of bias but in turn involves deeply ideological classifications. This is how ideology works: as Hall argues, ideology is not psychological or moralistic but structural and epistemological (Hall, 1977, p. 334).

In the following sections I will elaborate on this argument drawing heavily upon Daniel Hallin's notion spheres of consensus, controversy and deviance (Hallin, 1989) and Gramsci's concept of hegemony in Stuart Hall's reworking of it (Hall, 1977). But before that I would like to provide a brief narrative about my ethnographic observation and an inventory of the data I use for this essay to provide the reader with a kind of map to follow the different parts of my argument.

\section{Ethnographic Data}

The story of the day is a short news story about two events: United Farm Workers' (UWF) San Diego Support Committee - they are a group of Latino students at San Diego State University (SDSU), Sanchez tells me - arranged a rally to celebrate labor leader Dolores Huerta, and a Blood Drive by San Diego Blood Bank to help Huerta who recently had undergone a surgery. "She is big among Latinos, even if many may not know her" he explains: "basically it is two stories together, but the focus will be on Huerta with Blood Drive angle." He also tells me that he will write the story beforehand but he will go there to make sure that the rally is running as they describe it in their press release. "I am gonna say they [the activists] are doing it for Blood Drive." I ask whether the students actually say so. "Oh yeah, they do" he says but upon reading the press release, he realizes that this is only a small part of what they are promoting: "well, they cannot decide which angle we are going to put on it."

He explains also that he sees it as a public service story. I do not ask what he means by public service story assuming that he wants to inform his Latino readers about activities that are relevant for them. My assumption turns out to be wrong: Latinos are his beat; his imagined audience is the "white" readers - he mentions them simply as "people." This proves to be an important distinction that has tremendous implications for how the story is framed. If the story were 
written for Latino readers, it might have been shaped as a political story rather than human-interest story as his sources actually would like it. Public service story means consequently a human-interest story where people are called on to be involved in the event through the blood drive.

A phone call to San Diego Blood Bank and UFW changes a basic fact: "So she doesn't need blood anymore?" But this does not change the story, because "her need for blood made people aware of the need out there." He explains to me later that for every pint of blood that is donated will be credited to her medical bill by 10 dollars. After the phone calls -he cannot get hold of the activists - he begins writing the story without having talked to the activists, "because we already know what's going to happen." He leaves empty space just after the first paragraph for a quote from the activists. "After the quote, I am going to tell who she is, for people don't know her," he adds. But "who she is" is not given apriori as I realize later on; she needs to be described in a certain way to shape the story as a human interest story.

After a while, the editor comes to his desk and a short conversation takes place:

Editor: $\quad$ If they [Blood Bank] are still giving the tickets away, put that in [the first 50 donors will be given a $\$ 10$ discount voucher for tickets to the Luis Valdez play, The Mummified Deer].

Sanchez:

She has 11 children

Editor:

Put that in, too.

Sanchez:

She has been associated with labor movement, but now she contributes to create awareness around blood situation.

Editor: $\quad$ Maybe she will be remembered for two things.

The draft of the story is ready by 5.25 just before we leave the office for SDSU where the rally begins. It is here that I really realize what the arrangement is all about even though I already had seen the press release: The fast is an annual nationwide event where supporters of United Farm Workers (UFW) fast for 36 hours to symbolize those 36 days that Cesar Chavez (the co-founder and leader of UFW) fasted in 1988 as a part of his non-violent struggle to make grape growers to accept a contract with UFW. Sanchez tells the young activists what he wants to do with the story and interviews them. The activists emphasize the celebration of Cesar Chavez and Dolores Huerta's lives and struggle.

After the interviews we attend the rally for a while, and he phones in the two quotes he chooses. The working day ends and I conduct an open-ended interview with him in one of cafeterias at SDSU. I ask him about why he decided to write the story; what makes it newsworthy; what he means by public service story and finally his personal investment in the story. I get all the material that was available for the story: press releases, printouts of e-mails, a short biography of her, and the notes he has taken while making the phone calls.

\section{Theoretical Framework}

Journalists often have complex considerations and negotiations around how to frame and present a story for the editor and for the reader through the editor, but the complexity of these considerations and negotiations often goes unnoticed because their judgments are arrived at based on some seemingly neutral criteria of newsworthiness and objectivity, which themselves are cornerstones of what Gans calls "the journalistic paraideology" - "an untested and often untestable set of beliefs. That it is an ideology can be illustrated, if not demonstrated, by the fact that those who adhere to it do not conceive of it as ideology. Like other empiricists working within a dominant paradigm, journalists believe themselves to be objective" (Gans, 1980, p. 203).

Daniel Hallin's division of the journalistic world into three regions - spheres of consensus, legitimate controversy and deviance - provides a useful model to analyze how these complex considerations and negotiations take place (Hallin, 1989, pp. 116-118). In this model that can be visualized as concentric circle the middle region is the Sphere of Legitimate Controversy, which is the locus of journalistic objectivity. It is in this region the debates and contests between the legitimate parties are reported and treated with the virtues of objectivity and balance.

This region is bounded on one side by an inner circle or what Hallin calls the Sphere of Consensus. This is the region where journalists do not feel compelled to be objective or disinterested. On the contrary, the journalist's role is to advocate or celebrate what is conceived as of common values.

"And beyond the Sphere of Legitimate Controversy lies the Sphere of Deviance, the realm of those political actors and views which journalists and the political mainstream of the society reject as unworthy of being heard" (Hallin, 1989, p. 117). In this region objectivity and fairness once again fades away, and journalists play the role of exposing, condemning of excluding those who challenge the political consensus. This sphere marks out the limits of acceptable political conflict. 
The Sphere of Deviance and the Sphere of Consensus exclude each other's social and political subjects: the same subject (person A) can be reported within both spheres, but the difference will be in the discursive construction of the object as either, say, "the mother of eleven children" or "the political leader of a radical movement." Using Hallin's model, one can argue that the discursive work of representation makes the ideological difference.

In his article about the importance of settings in reporting, Hallin quotes from a story in LA Times on a guerilla attack in El Salvador (Hallin, 1986, p. 127). Central America is an intensely controversial topic in the United States, and stories on this region of the world would normally be reported within the realm of political controversy, but the example is not concerned with politics. How can a journalist report on a guerilla attack without being involved in politics? It is in this specific story done by personalizing the event and pushing the human dimensions of the attack into the center. The story focuses on the setting rather than the agents of the conflict. A report in this soft-news style takes the event out of the realm of political controversy. Hallin's focus with this story is different but the example illustrates how particular ways of reporting changes the implications of the news story.

\section{Softening Social Objects in News}

As I stated previously, I do not talk about social subjects of a story in an essentialist sense. First of all, the same subjects may be considered legitimate in one context while deviant in another. Furthermore, the same person may discursively be constructed as different subjects (mother versus leader) in order to fit her into the type of story that the journalist chooses to write.

When the topic is not considered to be controversial, it is usually treated as a consensus or deviance story (e.g. a story about the relatives to the American soldiers in war) without much reflection. Other times a potentially controversial topic is moved into the Sphere of Consensus. In these cases complex rhetorical strategies are at play to reorganize the story to fit into this sphere. The Blood Drive story is such one.

The San Diego Union Tribune could potentially have covered it as a political story about a Latino labor leader and linked it to the agricultural workers' current struggle for union contract in PictSweet Mushroom Farms in Ventura County as the press release from UWF - though not so clearly - brought this into attention. The rally not only launched a 36-hour fast to honor the labor leaders (Cesar Chavez and Dolores Huerta) but also kicked off a national boycott of PictSweet Mushrooms. After all Dolores Huerta fought precisely the same kind of fight that these workers were fighting now. Yet the reporter chose to cover it as a human-interest story. Why?

At first sight, the answer is simple: to get the story through the editor and to the newspaper as Sanchez explained to me. But if we keep asking why and how questions, the complex nature of considerations and negotiations to get the story into the newspaper becomes revealed. To get through the editors means that he has to convince his editor about the newsworthiness of the story. As Sanchez says, "the editors are not censors, they are also journalists and they have to determine what is newsworthy like a journalist." What makes a story newsworthy then? He refers to the century old journalistic commandment as to the criteria for newsworthiness: what-who-where-when-why of the news. But as Manoff and Schudson incisively point out, "these questions hide within their simplicity and their apparent common sense a whole framework of interpretation from which reporters - even the best and most "objective" reporter - operate, and necessarily so" (Manoff \& Schudson, 1986, p. 3). Sanchez precisely refers to these questions as if the answers are naturally given: "The 'who' would be a famous person, Dolores Huerta. The 'what' would be there was a Blood Drive and ... the 'why' had to do a lot with explaining.. um.. what.. explaining the actions, the rally, the action of young people who ran this rally, the inspiration behind it."

There are several problems with his explanation: the first and main problem is that the what-who-where-when-why questions can also be fully and perfectly answered even if the "what" was framed as a political story on celebration of two labor leaders and boycott of PictSweet Mushrooms. The "what" could therefore as well be framed as the celebration of labor leaders rather than the blood shortage.

Neither is the "who" that simple: he tells me a couple of times during the day that she is well-known among Latinos but "people" do not know her. (The mutually exclusive categories of "Latinos" and "people" have important implications for how the story is shaped. I will be discussing this distinction later.) The "who" as a famous person is, thus, not given but constructed by the reporter who refers to her affiliation with Vice President Al Gore. He had already told me that he would tell the readers "who" she was after the first quotation. Here, she is first of all described as a patient who because of her status as a celebrity draws attention to a general problem that affects all of us: blood shortage.

His answer to the "why" is also very ambiguous: the UFW activists emphasize the celebration of the labor leaders both in their press release and in the interviews. This ambiguity is also acknowledged by him during the interview: "The folks here [at the rally] probably wanted to it to be ... focused more on labor issues and the work they are trying to promote, maybe even to talk about Cesar Chavez as a state holiday." Ergo, the Blood Drive angel as the main frame of 
the story is chosen by the reporter - probably in negotiations with the editor - not by the sources. Neither is it implied by the event(s) - the rally or the Blood Drive.

\section{Newsworthiness by Negotiations}

Newsworthiness is, then, not implied by the event itself, or on the spot but achieved by negotiations beforehand. He admits it clearly during the interview upon my question that raising awareness about her on a health issue rather than a labor issue was critical to get the story to the paper: "If we don't get that element there, we don't have a story." This is a typical discourse situation: when asked about newsworthiness, he draws on one explanation while in another context he contradicts the same explanation. As Potter and Wetherell (1987) remind us, variability in accounts is a common phenomenon because discourses operate in a field of various and sometimes conflicting rationales that are utilized in accordance to the rhetorical context of the account.

His interpretations - as any interpretations of reality - are deeply rooted in ideological premises. In Gans' words, “the journalists' facts remain facts as long as the unconscious value and reality judgments that go into them are validated by "common sense"" (Gans, 1980, p. 186). Ideology is already implicated in the field of legitimate interpretations for what goes for news; in his choices between "preferred" and "excluded" versions of reality, but these are not necessarily his own choices. His answers to who-what-why questions indicate to an important factor in the decision to move the story into the Sphere of Consensus - that of the imagined readers embodied in the editor's person. The editor decides which the story gets in the paper, and in his words, "a lot of Latinos may know her very well, but there are a lot of people who don't know who she is. They may not care, but they may care a little bit more now that they read about her ... on a ... different issue [than labor]." Besides, "San Diego is not the most union-friendly county."

The readers of the newspaper are clearly imagined as white middle class population of San Diego and the nature of the readership interacts with the story. Newsworthiness is judged by the relevance of "what-who-why" to this readership. As Waisbord also notes, "middle class readers and audiences rarely respond to reports on issues that affect poor and marginal people" (Waisbord, 2000, p. 96). Consequently, the stories "concerning Latin American immigration to the U.S. and Latino civil rights, are rarely included on the mainstream national news media" (Rodriguez, 1999, p. 96). In order to get a story about Latino civil rights - as was the case with Dolores Huerta - to the mainstream news media such as Union Tribune, it needs to be de-politicized and de-ethnicized; it needs to be (re)articulated as a human-interest story within the Sphere of Consensus.

Both Waisbord's, Rodriguez's and my own observations testify against Michael Schudson's argument that "there is an acknowledged norm that stories of special interest to these groups [minority and women] are legitimate general-interest news stories" (Schudson, 2000b).

But de-politization and de-ethnicization of such a story is precisely a re-politization and re-ethnicization within the hegemonic conceptions of the social and ethnic hierarchies, and of what constitutes the Sphere of Legitimate Controversy - the American party system in election time (Hallin, 1986). As such, a struggle for Latino workers' rights would -if they get coverage at all - probably belong to the Sphere of Legitimate Controversy. However, in a union-unfriendly, dominantly white county like San Diego, union struggles may as well be seen as deviant and as a threat to community if covered but more often they are likely to be omitted from the coverage.

The categorization of readers as "people" and the beat that he is covering as "Latinos" are indications of hegemonic conceptions of ethnicity: people as the non-ethnic, norm-giving community from which Latinos by implication are excluded as outsiders or as the Other - a distinction by which the ethnic hierarchy is maintained. "People" here is hegemonic because although it signifies the white middle class population in San Diego, it refers to a universal norm. White ethnicity is not constructed as an alternative ethnic or racial category to its Latino Other among multiple ethnicities that constitute the "community" but rather outside the purview of ethnic discourse; it is absent in the discourse (so are the Latinos - there is not a single word in the whole news story that signifies ethnicity) but persistent as an unmarked position from which all these considerations are made, and from which facts (what-who-why) make sense. The "who" is a different person than she is for the Latinos, even if she was described as a Latino labor leader, which is why Sanchez avoids this signification. As a labor leader, she is a hero for the Latino community but a threat to "the unity of community" for the white reader, which is why she not only gets de-politicized and de-ethnicized but also is gendered/feminized. The editor wants the information that she is the mother of 11 children to be put in the story because, as Sanchez later explains me, "the sheer number of 11 regardless of race is worth mentioning in a context like this." "If you say 11 children receiving welfare, that's definitely a negative portrayal."

The "what" here is not only signified by what it is described as - the Blood Drive - but also by the remarkable absence of Latino labor struggle, which would connote a split in the community; a threat to the (white) majority by an ethnicized minority. The explicit purpose of this kind of stories is to underline the community - "it is a public service story." As Daniel Hallin writes, "creating a sense of belonging to a larger community is one of the basic functions of the 
newspaper." (Hallin, 1986, p. 118). In this sense "a story like this tells us, among other things, "who" we are as Americans, and "where we are in the sense of what kind of world surrounds us. How these questions are answered is probably much more important than the who-what-when-where-where-why of particular events, which will after all be quickly forgotten" (Hallin, 1986, p. 144). "But it is not always an unproblematic role: defining a community is a political act that can involve exclusion as well as inclusion, and stressing of certain interests and ties over other that might define the community in a different way" (Hallin, 1986, p. 118). Defining a community is not only a matter of content but also of form, or as Schudson notices, definitions relate to the world in "the way the world is incorporated into the unquestioned and unnoticed conventions of narration, then transfigured, no longer a subject for discussion but a premise for any conversation at all" (Schudson, 1982, p. 98).

Until now I have tried to elaborate my argument that the decision to frame the story within the Sphere of Consensus hides within its simplicity and its apparent common sense some underlying assumptions about the readership and its relationship with a minority group. This move has broader ideological implications because it fixes the sense of community against the absent but implied Other and reaffirms the sense of who "we" are as if it is naturally given, widely shared identity, not as a subject for discussion but as a premise for inclusion (or exclusion) at all.

\section{The Iron Cage of Ideology?}

However, this is not to say that the reporter is imprisoned within the iron cage of ideology and has no option but reproduce it. Neither is he unaware of the general ideological implications of the ways in which social objects are treated in the news. On the contrary, he is extremely aware of it. He explains me that one of the common complaints from the Latino community is that their events are not covered enough and "people" therefore do not know much about them. People's image of Latinos is based on television's distorted and stereotypical portrayal of them. He wants to challenge these images and write a story about Latinos not as victims or victimizers but as ordinary Americans who have villains and heroes among them in the same way as other people. He uses even a language that is not common to American journalists: he wants to educate his readers by raising awareness about one of the heroes of Latino population. As such his intention with this story is to break down the fixation of the Latino in the gaze of Otherness. Ideology does not work through him in an unconscious way. He speaks against the dominant ways of speaking of ethnicity in general and Latinos in particular.

If he ever can be described as unconscious about anything, it is certainly not about the implications of the news content but about the implications of "unquestioned and unnoticed conventions of narration" and of his belief in simplicity and taken-for-grantedness of the criteria of newsworthiness. In order to get the story to the paper in a way to avoid a stereotypical portrayal of the Latino population as either victims or victimizers, he erases ethnicity and class from the story. The Latinos are no longer present as an ethnic minority group or working class. Consequently the ethnic Other is not integrated into the "community" (which itself is constructed and fixed by this ethnic Other) by widening the definition of community but is kept in place by its absence (this ethnic Other may be explicitly represented in stories where ethnicity and class are signified negatively).

One of the functions of framing the story within the Sphere of Consensus is to avoid potential accusations of bias. Stories in this sphere are by definition outside controversy. But does his position as both a journalist and ethnic minority make him an advocate for the Latino community? Can he be described as an activist journalist rather than objective? He rejects any suggestion that his objectivity is at risk, but this is obviously a question that also bothers him: "raising the profile of the Latino does not necessarily mean that I am biased, for or against, but it speaks more to the presence of this population as Americans, because as you see most of the young people who are here today are ... most likely Americans..."

America Rodriguez reports that objectivity and its opposite, advocacy, are topics of daily discussion for Latino journalists (1999, p. 87). Her account indicates that Latino journalists try to break with the dichotomy of objectivity and advocacy but only half-heartedly: they still subscribe to objectivity as the basic tenant of their profession. The problem has to do with the dichotomy itself: its opposite positions are articulated within the dominant discourse of ethnicity. If we take the terms objectivity and advocacy for what they signify in the dominant discourse, Latino journalists who write from a Latino point of view would certainly be characterized as advocates for a particular group rather than as objective journalists. Particular group means particular interests. Against what? General interest? Is there such a thing as general interest, if general interest indeed is defined on the basis of the hegemonic (white) ethnicity? It is hegemonic in the sense that it is taken-for-granted, something that is outside reasoning, questioning, argument or logic. It does not appear as an ethnicity but the natural state of being; its very taken-for-grantedness renders invisible its own premises and presuppositions that are as particular and ideological. Objectivity in American journalism about ethnicity is therefore built upon a deep but invisible bias because, as Gans notes, the journalists "express, and often subscribe to, the economic, political, and social ideas and values which are dominant in America" (Gans, 1980, p. xv). Here again, the 
Latino journalists are perfectly aware of this when they defend themselves by pointing at the "bias" that "general market" journalists also have: ignoring and distorting Latino communities they cannot be truly objective (Rodriguez, 1999, p. 88).

\section{Concluding Qualifications}

I need to bring in some qualifications about some potential misunderstandings of my argument. First of all, my argument in this paper is not that the ideological content of a news story is determined once for all. As I implied earlier on, utterances such as news stories are rarely homogenous; it consists of multiple voices that pulls the text in various directions, although we may also recognize a dominant perspective in an utterance. This multiplicity can also be found across utterances. As Sanchez kindly reminded me after having read one of the earlier drafts of this paper, Union Tribune publishes stories on labor issues and particularly Dolores Huerta as a labor union. What this paper argues is not, then, that there is a dominant ideology that pervades all news stories about Latinos, but that simple descriptive stories such as this one are products of complex negotiations in the whole production process. And a second point is that an ethnographic approach can add a crucial dimension to understanding the ways in which meaning is negotiated in news stories. A study of audience reception would furthermore contribute to an understanding of meaning production at the moment of the text's consumption.

There is also a qualification to be made on the nature of hegemony. There is an inherent danger with explaining the ideological effect of the media with the concept of hegemony, if hegemony is understood as the dominance of a coherent ideology that pervades everything. Analysis that draws on the concept of hegemony often ends with conclusions on the ever taming, domesticating, incorporating abilities of the dominant ideologies (Todd Gitlin's otherwise impressive work, The whole world is watching (1980) is one example, although he emphasizes the contingent nature of hegemony on several occasions) ${ }^{1}$. While it is Gitlin's analysis that implies the reinforcing power of hegemony, it is more explicit in other scholarly writings. One example is Benson (2000) who argues that "the Gramscian concept of hegemony ... [shows] how journalistic practices and organizational procedures operate to effectively reinforce established political and economic power. But hegemony's essentially functionalist assumptions ignore the ways in which media systems do not always reinforce the power status quo, but under certain conditions may actually transform power relations in other fields" (Benson, 2000, p. 10). Schudson (2000a) also makes a similar criticism of hegemony theory which he thinks explains far too much.

However, this conclusion is not inherent in Gramsci's concept of hegemony. Gramsci was the leader of the Italian communist party and interested in transforming Italy into a socialist system. In other words, he was mainly interested in change, not merely in the explication of the reinforcing powers of dominant classes. He understood that socialist intervention had to be made not only in the sphere of political controversy but primarily in the ideological terrain where the working class consciousness was fragmented and episodic, and thus not in harmony with its "real" interests. His primary interest was to make working-class ideology into common sense.

One of the main points in Gramscian concept of hegemony is that it is not given for all times: it has to be maintained through an ongoing ideological struggle for defining and redefining the world and its conflicts. Gramsci makes a clear distinction, particularly in his notes on philosophy, between common sense and ideology. According to Gramsci, ideology operates at two different levels: at a philosophical level at which it articulates a systematic conception of the world, and at the practical level, at the level of common sense. The philosophical coherence of an ideology does not guarantee its effectiveness. Ideologies are only effective where their philosophical currents transform the everyday consciousness of the people. This everyday consciousness or the popular thought is what he calls common sense. Common sense, which is the level of basic and commonly agreed, consensual wisdoms, is not coherent, but rather disjointed and episodic. "Every philosophical current leaves behind a sediment of 'common sense'; this is the document of its historical effectiveness. Common sense is not rigid and immobile but is continually transforming itself, enriching itself with scientific ideas and with philosophical opinions which have entered ordinary life." (Gramsci, 1971, p. 326, fn. 5)

Now understood in this way (as a terrain on which meaning are flexibly constructed), common sense is not necessarily totally dominated by 'ruling class ideology' or any kind of ideology per se. Rather, it is the terrain on which contesting philosophical currents have left their sediments, transforming it into a new set of narratives that also contain oppositional conceptions of the world. Hegemony is when some of these conceptions that do not have a necessary relationship with one another are articulated together to describe social relationships in terms of a set of antagonisms (Laclau \& Mouffe, 1985). In this perspective, The San Diego Union Tribune's article and the negotiations around the production of it make sense in an antagonistic relationship between two ethnicities, or rather a particular ethnicity (Latino) and its opposite, which is non-ethnicity for which whiteness stand for. 
Hegemony is an abstract theory of the contingency of the social, which is concerned with the production of the social as an unstable fixation of meaning in language. However, language is not an abstract, static system that can be approached at an abstract level: it exists only through usage. It is only through usage that ideology can be observed and identified, not in terms of abstract thought systems but as a particular effect of language use. But it is also because of this that meaning can never completely be fixed and hegemony becomes stabilized as the dominance of a coherent ideology that pervades everything, for "speech-acts do not exactly reproduce previous acts. This implies that ideology, because it is realized in acts of language, is also in a state of constant change, or creativity. Yet, at the same time, these acts of language are shaped by the social and historical context" (Billig, 1997, p. 217).

This perspective brings us to Bakhtin's notion of multiaccentuality (Volosinov, 1973) ${ }^{2}$ or heteroglossia (Bakhtin, 1981) at the level of utterance (of which The San Diego Union Tribune's story is example). Both concepts mean multiplicity of social voices in language. According to Bakhtin, "language is not an abstract system of normative form but rather a concrete heteroglot conception of the world" (Bakhtin, 1981, p. 293): it represents the co-existence of socio-ideological contradictions. Language is the site of struggle between centripetal and centrifugal forces. Centripetal forces struggle to overcome heteroglossia of language by uniting and centralizing verbal-ideological thought. Centrifugal forces, on the other hand, serve to stratify the language through decentralization and disunification. Both forces are present in every utterance. "Class [and ethnic group] does not coincide with the sign community, i.e., with the community which is the totality of users of the same set of signs for ideological communication. Thus various different classes [and ethnic groups] will use one and the same language. As a result, differently oriented accents intersect in every ideological sign. Sign becomes an arena of the class struggle" (Volosinov, 1973, p. 23) "The word in language is half some else's. It becomes "one's own" only when the speaker populates it with his own intention, his own accent, when he appropriates the world, adapting it to his own semantic and expressive intention" (Bakhtin, 1981, p. 293). The heteroglossia of language; the multiaccentuality of the ideological sign precisely constitutes necessary spaces in the discourse where others than dominant groups can insert themselves.

I have full sympathy for Leonel Sanchez and his editor. And I have sympathy for his project, which indicates - however limited - that there is an awareness to include minorities in the news also as ordinary people. But to go back to Gans, values in news are different from value implications of the news. What I have tried to do in this paper was to draw attention to the symbolic organization of a particular news story which is the result of a complex process of negotiations, and to analyze the value implications of the output. Having said this, I should also add that it is difficult if not impossible to "measure" the effect of such a story. One way of studying its impact would have been to bring together a focus group of typical (white) readers and observe them reading, discussing and interpreting the story. On the other side, people's interpretations are influenced by the actual contexts they are read and discussed in. And through such a study it would be difficult to say something certain about what a single story means in interaction with all the other stories, their frames, ideological accentuations, etc. to which we are constantly exposed. We can only theorize how this piece may fit into a broader context of hegemonic articulation.

\section{References}

Bakhtin, M. M. (1981). (edited by M. Holquist). The Dialogical Imagination: Four Essays. Austin: University of Texas Press.

Benson, R. D. (2000). Shaping the Public Sphere: Journalistic Fields and Immigration Debates in the United States and France, 1973-1994. (Unpublished doctoral dissertation). Department of Sociology, University of California, Berkeley.

Billig, M. (1997). From Codes to Utterances: Cultural Studies, Discourse and Psychology. In M. Ferguson \& P. Golding (Eds.) Cultural Studies in Question. (pp. 205-226). Thousand Oaks, CA: Sage.

Fairclough, N. (1992). Discourse and Social Change. Cambridge: Polity Press.

Fairclough, N. (1995). Critical Discourse Analysis: Papers in the Critical Study of Language. Harlow: Longman.

Gamson, W. A., Croteau, D. C., Hoynes, W., \& Sasson, T. (1992). Media images and the social construction of reality. Annual Review of Sociology, 18, 373-393. http://dx.doi.org/10.1146/annurev.so.18.080192.002105

Gans, H. J. (1980). Deciding What's News. A Study of CBS Evening News, NBC Nightly News, Newsweek and Time. New York: Vintage Books.

Gitlin, T. (1980). The Whole World is Watching: Mass Media in the Making and Unmaking of the New Left. Berkeley: University of California Press.

Gramsci, A. (1971). (edited and translated by Q. Hoare and G.N. Smith). Selections from the Prison Notebooks. London: Lawrence and Wishart. 
Hall, S. (1977). Culture, the Media and the 'Ideological Effect'. In J. Curran, M. Gurevitch and J. Woolacott (Eds.), Mass Communication and Society (pp. 128-138). London: Arnold.

Hallin, D. C. (1986). Cartography, Community, and the Cold War. In R. K. Manoff \& M. Schudson (Eds.), Reading the News (pp. 109-145). New York: Pantheon Books.

Hallin, D. C. (1989). The Uncensored War: The Media and Vietnam. Berkeley: University of California Press.

Hallin, D. C. (1994). We Keep America on Top of the World: Television Journalism and the Public Sphere. New York: Routledge.

Hallin, D. C. (2000). Commercialization and Professionalization in the American News Media. In J. Curran and M. Gurevitch (eds), Mass Media and Society. London, Arnold.

Laclau, E., \& C. Mouffe (1985). Hegemony and Socialist strategy: Towards a Radical Democratic Politics. London: Verso.

Manoff, R. K., \& Schudson M. (1986). Reading the News. In R. K. Manoff \& M. Schudson (Eds.), Reading the News: A Pantheon Guide to Popular Culture (pp. 3-37). New York: Pantheon.

Potter, J., \& M. Wetherell. (1987). Discourse and Social Psychology. Beyond Attitudes and Behaviour. London: Sage.

Rodriguez, A. (1999). Making Latino News. Race, Language, Class. Thousand Oaks, CA: Sage.

Schudson, M. (1982). The Politics of Narrative Form: The Emergence of news conventions in print and television. Daedalus, 111, 97-113.

Schudson, M. (2000a). The Sociology of News Production Revisited (Again). In J. Curran \& M. Gurevitch (Eds.), Mass Media and Society (pp. 175-200). London: Arnold.

Schudson, M. (2000b, May 18-19). Changes in Journalistic Practice since 1960: The United States. Paper presented in French-American Conference. Berkeley.

Volosinov, V. N. (1973). Marxism and The Philosophy of Language. New York: Seminar Press.

Waisbord, S. (2000). Watchdog Journalism in South America: News, Accountability, and Democracy. New York: Columbia University Press.

\section{Notes}

Note 1. Gitlin concludes further that by excluding and taming, the media reinforced the dominant order in American political life. Now, this conclusion is not, in my opinion, so much determined by his actual analysis, but refers more to his understanding of hegemony as the dominance of a coherent ideology of the ruling elite, which pervades everything. He understands the flexibility of hegemony as its flexibility of taming and absorbing contesting ideas into the dominant ideology so to maintain the hegemony (see Gamson et.al. 1992, p. 380 for reflections on this reading). The fragmented nature of common sense implies, for Gitlin, that the fragmentedness is that which allows common sense to adopt and incorporate oppositional views. But this reading implies, on the other hand, that Gitlin understands common sense as more or less as the dominant ideology itself. Then a question poises itself: if every change in the dominant discourse is to be understood as taming and domestication of oppositional ideas, when does a dominant ideology, then, cease to be the dominant ideology? Or to poise the question in another way: Should changes only be conceptualized as changes, when and if they only happens as sudden ruptures, breaking down the existing scheme of the order totally, as in the case of a revolution?

Note 2. It is generally accepted that Bakhtin published two books under Valentin Volosinov's name.

\section{(cc) $\mathrm{EY}$}

This work is licensed under a Creative Commons Attribution 3.0 License. 